\title{
TEORIAS SOCIOLÓGICAS SOBRE A CRIMINALIDADE. ANÁLISE COMPARATIVA DE TRÊS TEORIAS COMPLEMENTARES
}

\author{
SOCIOLOGICAL THEORIES ON CRIME. \\ COMPARATIVE ANALYSIS OF THREE COMPLEMENTARY THEORIES
}

\author{
Jair Araújo de Lima ${ }^{1}$ \\ Juliane Ramalho dos Santos $^{2}$ \\ Polyanna Pinheiro Dal' $\mathrm{Col}^{3}$ \\ Samara Fiorio da Silva ${ }^{4}$
}

\begin{abstract}
RESUMO: O artigo faz uma análise comparativa de três teorias sociológicas sobre a criminalidade: a Teoria da Associação Diferencial (ou Aprendizagem Social) de Edwin H. Sutherland, a Teoria do Autocontrole de Michael R. Gottfredson e Travis Rirch e a Teoria da Anomia (strain) de Robert K. Merton. A nossa análise acaba por demonstrar que estas três teorias podem ser compreendidas como convergentes e complementares. Concluímos apontando que, entre tantas teorias sociológicas do crime, estas três podem ser utilizadas para a análise sociológica, de maneira que uma venha preencher adequadamente as lacunas da outra. A sociologia do crime está bem servida de teorias que tentam explicar - cada uma com pretensões de exaustividade - o fenômeno do crime. Assim, postulamos (neste texto) que podemos (e devemos) fazer um uso combinado de teorias (sobre o crime) que se complementem e venha a explicar os fenômenos do crime em sua constitutiva transversalidade.
\end{abstract}

Palavras-Chave: Crime, Sociologia do Crime, Teoria da Associação Diferencial, Teoria do Autocontrole, Teoria da Anomia.

\footnotetext{
ABSTRACT: The article makes a comparative analysis of three sociological theories on crime: Edwin H. Sutherland's Theory of Differential Association (or Social Learning), Michael R. Gottfredson's and Travis Rirch's Theory of Self-Control, and the Anomie (or strain) Theory by Robert K. Merton. Our analysis shows that these three theories can be understood as convergent and complementary. We conclude by pointing out that, among so many sociological theories of crime, these three can be used for sociological analysis, so that one adequately fills the gaps of the other. The sociology of crime is well served by theories that try to explain - each with pretensions of completeness - the phenomenon of crime. Thus, we postulate (in this text) that we can (and must) make a combined use of theories (on crime) that complement each other and explain the phenomena of crime in its constitutive transversality.

${ }^{1}$ Doutorando em Ciências Sociais - PUC/Minas.

${ }^{2}$ Psiquiatra, graduada em Medicina na UNIFESO/RJ, especialista em Psiquiatria pela Universidade Gama Filho/RJ.

${ }^{3}$ Graduanda em Medicina - PUC/Minas.

${ }^{4}$ Graduanda em Medicina - PUC/Minas.
} 
Keywords: Crime, Sociology of Crime, Theory of Differential Association, Theory of Self-control, Anomie Theory.

\section{INTRODUÇÃO}

Os estudos sociológicos sobre as causas da criminalidade têm sido elaborados segundo duas direções, ora complementares, ora opostas (PATERNOSTER ; BACHMAN,2001; ROBERT, 2005). Uma primeira direção que os estudos sociológicos privilegiam é a macrossociológica. Neste sentido, são valorizadas as variáveis processuais, estruturais e institucionais que incidem sobre a etiologia ${ }^{5}$ dos crimes cometidos. Uma primeira questão aqui é saber quais são os elementos macrossociais que pesam sobre o sujeito e o fazem cair (ou o laçam) no mundo do crime. Uma segunda questão, ainda dentro desse arcabouço, é como esses elementos atuam. Aqui se analisa o peso dos determinantes políticos, culturais, econômicos e dos contextos sociais mais amplo e sua influência sobre os indivíduos que cometem crimes. Fala-se de uma causa social da criminalidade.

Há, contudo, uma segunda direção que alguns sociólogos privilegiam para abordar os determinantes da entrada no mundo do crime, neste segundo caminho os estudiosos (sociólogos ou não) focalizam numa dimensão microssociológica, apontando - junto com psicólogos, economistas e, até mesmo, psiquiatras - que são as características individuais e as motivações dos sujeitos que realizam os delitos que os encaminham para o mundo do crime. Neste limiar, interessam os elementos biopsicológicos, a estrutura cerebral, os traços de personalidade e temperamento, os backgrounds cognitivos e os elementos de decisão racional dos indivíduos (BECKER, 1968; GOTTFREDSON ; HIRSCHI,1990; PATERNOSTER; BACHMAN,2001). O contexto mais amplo - geralmente - admitido nesta linha de investigação são as relações interpessoais com os familiares mais próximos (pais e irmãos), grupos de amigos da mesma faixa etária. No geral, fala-se de uma causa individual do crime. Como já foi dito, as miradas teóricas que explicam o comportamento criminoso a partir de patologias individuais, sinalizam para três grupos de variáveis: de natureza biológica (temperamento, traços fisiológicos, etc.), psicológica (backgrounds

\footnotetext{
${ }^{5}$ Etiologia (do grego aitía, "causa") é o estudo ou ciência das causas/fontes de uma determinada consequência. No contexto da sociologia do crime, trata-se do estudo das causas/fontes do crime (Cf. DALGALARRONDO, 2000; KAPLAN; SADOCK; SADOCK, 2007).
} 
cognitivos, trajetória de vida, etc.) e psiquiátrica (traços de personalidade, estrutura cerebral, patologias, etc. $)^{6}$.

Neste trabalho, faremos uso de três teorias com vistas a estabelecer uma análise comparativa que procura exemplificar como as três teorias se diferenciam na explicação das causas do crime, levando em conta os níveis de análise (individual, interpessoal, institucional e estrutural). Eventuais pontos de convergência e complementariedades serão aludidos.

\section{I - A TEORIA DA ASSOCIAÇÃO DIFERENCIAL (APRENDIZAGEM SOCIAL) DE EDWIN H. SUTHERLAND}

\subsection{APRESENTAÇÃO}

Sutherland estava interessado em se afastar das explicações biológicas e raciais sobre o crime (ROBERT, 2005). Sendo este o seu interesse, foi levado ao estudo da criminalidade sistemática. Numa de suas pesquisas fundamentais relatou - por meio de uma entrevista transformada num estudo de caso - a vida de um ladrão profissional (The professional thief, 1937). Buscou afastar-se das pesquisas de crime entre as classes populares e dedicou-se ao White collar crime (1949). Assim, chegou à elaboração de sua teoria da associação diferencial (ou do aprendizado social). ${ }^{7}$ Sua teoria considera o crime como um comportamento aprendido pode meio da socialização/interiorização de comportamentos específicos baseados da interação entre pares que adotam modelos culturais relacionados à delinquência social.

Influenciado pela ecologia urbana $^{8}$, a qual apontava para a desorganização social como elemento influenciador da criminalidade, Sutherland se utiliza da noção de “desorganização" em sua elaboração do conceito de organização social diferenciada que

\footnotetext{
${ }^{6}$ No campo brasileiro, Cerqueira e Lobão (2004) ofereceram, num artigo ainda não superado, um panorama completo das teorias sobre o crime que se confrontam na sociologia do crime. Eles expõem que as teorias do crime tendem para explicações em três níveis: (a) estrutural/institucional, (b) interpessoal e (c) individual.

${ }^{7}$ Sutherland aborda a sua teoria da associação diferencial - conforme Robert (2005) - na reedição de 1939 do seu texto (original de 1934) Criminology (Chicago/Philadelphia/New York: Lippincott).

${ }^{8}$ Inspirada em escritos de autores da Escola de Chicago como Robert Park e Louis Wirth, entre outros.

${ }^{9}$ Conceito relacionado à noção de "desorganização social", caro aos primeiros autores da Escola de Chicago, como William I. Thomas e Florian Znaniecki. Jacobs (2000) apoiou-se neste conceito de "desorganização social" para elaborar a sua própria concepção ecológica do crime. A crítica mais conhecida ao conceito de "desorganização social" foi feita, na própria Universidade de Chicago, por William Foote Whyte em 1943 (Cf.WHYTE,2005). Nos textos de Sutherland, a noção de "associação diferencial" está contextualmente relacionada ao conceito de "desorganização social", como poderemos examinar adiante.
} 
conduzia à aprendizagem social de normas e procedimentos. Deste modo, a socialização num grupo que adota modelos culturais contrários à honestidade e ao respeito das leis engendra o criminoso. As teorias da subcultura ${ }^{10}$ foram igualmente úteis para Sutherland elaborar a sua própria teoria do crime (ROBERT, 2005). Desta maneira, emerge a compreensão de se que o crime procede da "desorganização social"11, mas de uma organização diferencial e da aprendizagem num meio cultural específico.

A partir das (nove) proposições ${ }^{12}$ elaboradas por Sutherland sobre a tua teoria, podemos deduzir que para Sutherland as bases da conduta humana têm suas raízes na experiência cotidiana e no aprendizado que ela implica. O indivíduo atua de acordo com as reações que sua própria conduta desperta nos outros e que o comportamento dos outros desperta nele ${ }^{13}$. Assim, o comportamento individual acha-se permanentemente modelado ${ }^{14}$ pelas socializações da vida cotidiana. Contrariando as perspectivas que ele

\begin{abstract}
${ }^{10}$ O conceito de "subcultura" é caro, sobretudo, a Robert K. Merton (Cf. MERTON, 1970). Cohen (1955) elaborou a sua teoria da subcultura da delinquência. Burton R. Clark ilustrou como os jovens vivenciam as diversas subculturas juvenis - subcultura "da diversão", subcultura "colegial", subcultura "acadêmica", subcultura "vocacional" e, por fim, subcultura "delinquente". (CLARK, 1962).

${ }^{11}$ Chinoy (1975) oferece um conceito de "desorganização social" mais amplo do que aquele elaborado pela ecologia urbana, para a qual a "desorganização social" é o mesmo que "deterioração do espaço social e/ou grupal". Assim, uma paisagem social deteriorada implica uma "desorganização social" que leva ao crime. É com este conceito que Sutherland dialoga, como veremos adiante em citação direta de Sutherland. O conceito de Chinoy (1975) parece-nos muito útil a uma análise sociológica do crime. Segundo ele: "A desorganização social é um conceito inclusivo, que abrange fenômenos variados, como o conflito de papéis, o conflito cultural, a disjunção entre meios e fins socialmente sancionados e outras espécies de incongruências ou contradições." (CHINOY, 1975, p.646, grifo original). Note-se que Chinoy aloca "o conflito cultural, a disjunção entre meios e fins socialmente sancionados" (presentes no conceito mertoniano de "strain" (tensão), como fenômenos de desorganização social.

${ }^{12}$ As nove proposições são: 1) O comportamento criminal é aprendido; 2) O comportamento criminal é aprendido em interação com outras pessoas em um processo de comunicação; 3) A parte principal da aprendizagem do comportamento criminoso ocorre dentro de grupos pessoais íntimos; 4) Quando o comportamento criminoso é aprendido, a aprendizagem inclui (a) técnicas de cometer o crime, às vezes muito complicadas, às vezes muito simples, e (b) a direção específica de motivos, motivações, racionalizações e atitudes; 5) A direção específica dos motivos e unidades é aprendida com as definições dos códigos legais como favoráveis ou desfavoráveis; 6) Uma pessoa se torna delinquente devido ao excesso de definições favoráveis à violação da lei sobre definições desfavoráveis à violação da lei; 7) As associações diferenciais podem variar em frequência, duração, prioridade e intensidade; 8) O processo de aprender comportamento criminal por associação com padrões criminais e anti-criminosos envolve todos os mecanismos envolvidos em qualquer outro aprendizado; 9) Embora o comportamento criminoso seja uma expressão de necessidades e valores gerais, não é explicado por essas necessidades e valores gerais, porque o comportamento não criminoso é uma expressão das mesmas necessidades e valores.
\end{abstract}

${ }^{13}$ Sutherland é amplamente devedor da teoria do "outro generalizado" de George Herbert Mead (Cf. MEAD, 1968).

${ }^{14}$ No behaviorismo social de Mead (1968) a "modelagem" - Mead inspirava-se tanto em Gabriel Tarde (TARDE, 2000) quanto em Watson - consiste num comportamento reflexivo de imitar um modelo de comportamento bem sucedido, do ponto de vista do seguidor do comportamento modelo. Em sua proposta, Sutherland - embora devedor a Mead em seu conceito de "aprendizagem cultural" - levam conta, também, o conceito skinneriano de "modelagem", isto é, o ato de reforçar as aproximações sucessivas tendo por fim um comportamento desejado. Sutherland, com efeito, não abre mão do elemento "reflexivo" do ator de "modelagem", presente em Mead. 
denomina "convencionais", Sutherland propõe que a conduta criminosa não é algo anormal, não é sinal de uma personalidade imatura, de um déficit de inteligência, antes é um comportamento adquirido por meio do aprendizado que resulta da socialização num determinado meio social.

Em suas investigações sobre o White collar crime, Sutherland aborda a delinquência econômica e profissional e o nível de inteligência do infrator, então conclui que a conduta desviada não pode ser imputada a déficits de inteligência dos infratores. Também não se trata de inadequação dos indivíduos das classes desfavorecidas socioeconomicamente (SUTHERLAND, 2014 [1940], p.101), mas de uma aprendizagem efetiva dos valores criminais, algo que pode suceder em qualquer meio de qualquer cultura.

Finalmente, a conduta criminal é aprendida em interação com outras pessoas, mediante um processo de comunicação. Pelo que requer uma postura ativa da parte do indivíduo que aprende. O crime não é hereditário nem é algo fortuito ou irracional, é uma conduta aprendida. As pessoas se tornam delinquentes devido a um excesso de definições favoráveis à violação da lei, em detrimento de definições não favoráveis à tal violação. $\mathrm{O}$ processo de aprendizado de comportamentos criminosos envolve todos os mecanismos que estão envolvidos em qualquer outro aprendizado - tais como reforço diferencial ${ }^{15}$, imitação $^{16}$, definições da situação $^{17}$ e associação diferencial ${ }^{18}$. Embora exista o suposto de uma hipersocialização, adverte-se que o criminoso não possui um sistema moral homogêneo nem manifesta comportamento homogêneo.

\subsection{ANÁLISE COMPARATIVA}

Conforme já apontado supra, Sutherland recebeu influência de ecologia urbana (Cf. FREITAS, 2004) e da teoria das subculturas ${ }^{19}$. Da primeira, ele se afastou pela

\footnotetext{
${ }^{15}$ Implicado no conceito skinneriano de "modelagem".

${ }^{16}$ Conceito de Gabriel Tarde (Cf. TARDE, 2000), significando "mimese", comportamento imitativo.

${ }^{17}$ Conceito caro a William I. Thomas e Dorothy Swaine Thomas (Cf. THOMAS; THOMAS, 1928). Robert K. Merton o tornou amplamente conhecido como o "teorema de Thomas". O teorema de Thomas postula que: "Se as pessoas definem certas situações como reais, elas são reais em suas consequências."

${ }^{18}$ Conceito diretamente relacionado ao de "organização social".

${ }^{19}$ Os nomes associados à (s) teoria (s) da (s) subcultura (s) do crime são: Edwin H. Sutherland, William Foote Whyte, Albert K. Cohen, Richard Cloward e Lloyd Ohlin, David Matza e Gresham Sykes, entre outros. Para os fins deste artigo, assumimos que Edwin H. Sutherland consiste no nome mais representativo desta teoria. Mas, os textos de Albert K. Cohen, Richard Cloward e Lloyd Ohlin, David Matza e Gresham Sykes sobre este assunto são fundamentais para uma compreensão completa - impossível no escopo deste artigo - desta importante corrente da sociologia do crime. A (s) teoria (s) da (s) subcultura (s_) do crime
} 
recusa da noção de "desorganização", assumindo a conceito de "organização diferencial". Da segunda, ele reteve a noção de "socialização cultural específica", mas recusou a noção de imitação passiva ${ }^{20}$.

A teoria de Sutherland pode ser situada no nível interpessoal de análise do crime. Por isso, Cerqueira e Lobão (2004) apontam que: "Nesse sentido, a família, os grupos de amizade e a comunidade ocupam papel central." (p.241).

Robert (2005) situa a teoria de Sutherland entre as "teorias culturalistas" (cf.pp.100-107) do crime e sugere que "a hipótese cultural, ao libertar o indivíduo das suspeitas da diferença individual, transfere-as aos grupos com os quais o mesmo se identifica." (ROBERT, 2005, pp.106-107).

Da parte do próprio Sutherland, ele afirmar que pretende "integrar [...] duas áreas de conhecimento" (SUTHERLAND, 2014 [1940], p.93), a sociológica (que era familiar ao crime, mas não habituada a considerá-lo como manifestação nos negócios) e a econômica (que conhecia as técnicas de negócios, porém não acostumada a analisá-las do ponto de vista do crime). Outro objetivo de Sutherland era demonstrar que as "teorias convencionais" sobre o crime eram inválidas, sobretudo, por serem fruto de amostras viciadas. Sutherland (2014 [1940]) formula:

Os criminólogos têm utilizado estudos de caso e estatísticas criminais derivados dessas agências da justiça criminal como sua principal base de dados. Assim, a partir dessas, eles formularam teorias gerais do comportamento criminoso e sustentam que, uma vez que o crime está concentrado na classe baixa, ele é causado pela pobreza ou características pessoais e sociais que acreditam estar estatisticamente associadas com a pobreza, incluindo enfermidades mentais, desvios psicopáticos, bairros carentes e famílias "degeneradas". (p.94).

Ele sustenta, então, que "o crime não se concentra tanto na classe baixa como as estatísticas convencionais apontam.” (SUTHERLAND, 2014 [1940], p.97) ${ }^{21}$. E, ainda, que: "A teoria de que o comportamento criminoso em geral se deve à pobreza ou às

fundamentadas em insights da ecologia urbana (primeira escola de Chicago de sociologia) e das primeiras noções de Robert K. Merton sobre "subcultura".

${ }^{20}$ Como informado anteriormente, Sutherland prefere o termo "modelagem" ao de "imitação". Ele faz uso de termo skinneriando "modelagem", mas fazendo uma combinação entre Skinner e Mead. Assim, a "modelagem" é uma método de aproximações sucessivas (tal qual em Skinner). Mas, tal como em Mead (1968), a modelagem é "reflexiva", não apenas um comportamento adotado de modo passivo, por meio de reforços que atuam sobre o comportamento.

${ }^{21}$ Sutherland refere-se às estatísticas oficiais, de sua época, a partir das quais alguns teóricos elaboraram a sua teoria do crime. 
condições psicopáticas e sociopáticas associadas com aquela, pode ser considerada inválida [...].”. (SUTHERLAND, 2014 [1940], p.101). Ele apresenta como "razões":

1) “[...] a generalização é baseada em uma amostra enviesada que omite quase que completamente o comportamento de criminosos de colarinho branco." (SUTHERLAND, 2014 [1940], p.101);

2) “[...] a generalização de que a criminalidade está estritamente associada com a pobreza, obviamente, não se aplica aos criminosos de colarinho branco." (SUTHERLAND, 2014 [1940], p.101);

3) “[...] as teorias convencionais não explicam sequer a criminalidade da classe baixa." (SUTHERLAND, 2014 [1940], p.101).

Sutherland, abertamente, está se opondo às criminologias individualistas e às estruturais, ele pretende que a sua elaboração teórica esteja situada no nível interpessoal - cultural segundo Robert (2005) - da análise social.

Há, particularmente no artigo sobre "A criminalidade de colarinho branco" (2014 [1940]), indícios de que há pontos de convergência da perspectiva de Sutherland com teorias que precederam e sucederam a sua iniciativa teórica. Em consonância com a teoria da trajetória de vida, Sutherland (2014 [1940]) assume que é legítimo "considerar as histórias de vida de tais criminosos como base de dados." (p.99). A trajetória de vida não seria um fundamento etiológico para o cometimento de crime, mas seria uma "base de dados" para a pesquisa criminológica.

Outro ponto importante, é que Sutherland, de maneira semelhante ao da teoria das atividades rotineiras ${ }^{22}$ (ou das oportunidades), concebe que existe uma "vulnerabilidade das vítimas" (SUTHERLAND (2014 [1940]), p.101).

Com alguma semelhança à teoria da escolha racional do crime, de Gary S. Becker, Sutherland propõe que: “Grupos e pessoas são individualistas; eles estão mais preocupados com os próprios interesses do que com o bem-estar comum." (SUTHERLAND, 2014 [1940], p.103) ${ }^{23}$.

\footnotetext{
22 Conferir Cohen e Felson (1979).

${ }^{23}$ Não é difícil supor que alguns adeptos da teoria da Sutherland não aceitem associar algumas de suas afirmações às formulações da Gary S. Becker, mas, a afirmação extraída é absolutamente semelhante ao postulado fundamental de Becker. Sendo evidente que, em termos mais gerais, Sutherland está consideravelmente distante de Gary S. Becker.
} 
Com efeito, a teorização de Sutherland complementa ${ }^{24}$ as perspectivas que vêm na pobreza a origem dos crimes. Segundo Sutherland: (a) embora, tais teorias possam explicar os crimes violentos ou coercitivos, (b) elas não explicam os crimes de colarinho branco, os quais "não usam métodos coercitivos" (SUTHERLAND, 2014 [1940], p.99).

De um modo surpreendente, a concepção de Sutherland é devedora da teoria da subcultura do crime $^{25}$, da criminologia ambiental ${ }^{26}$ e antecipa questões da teoria da eficácia coletiva ${ }^{27}$. Todas essas influências podem ser detectadas na obra geral de Sutherland, mas um trecho do seu artigo sobre o crime de colarinho branco evoca todas elas como se pode observar:

A associação diferencial culmina no crime porque a comunidade não é organizada o bastante contra aquele comportamento. A lei age em uma direção, enquanto outras forças atuam em sentido contrário. No mercado, as "regras do jogo" entram em conflito com as regras jurídicas. Um empresário que busca obedecer à lei é impelido por seus competidores a adotar os métodos deles. Isto é bem evidenciado pela persistência da corrupção privada em que pese os esforços extenuantes de organizações econômicas para eliminá-la. [...]. Consequentemente, não é possível para a comunidade oferecer uma firme oposição ao crime. Os órgãos de defesa do consumidor e comissões de prevenção ao crime, compostas por empresários e outros profissionais, combatem furtos, roubos e fraudes inexpressivas, mas são negligentes em relação aos os crimes de seus próprios membros. As forças que incidem sobre a classe baixa também estão em conflito. A desorganização social afeta as duas classes de maneira semelhante. (SUTHERLAND, 2014 [1940], p.103, grifo nosso).

É deste modo que a teoria da associação diferencial traça um modelo teórico generalizador, capaz de explicar a criminalidade das classes médias e da classe alta. Com ela Sutherland contribuiu para fundamentar estudos que encontram na noção genérica de “aprendizagem" uma referência fundamental.

\footnotetext{
${ }^{24}$ Isto é, preenche as lacunas que aquelas deixam abertas.

${ }^{25}$ Conforme já informamos em notas anteriores.

${ }^{26}$ Sutherland levou em consideração o que postulavam os teóricos da "desorganização social" e tomou "o conceito de desorganização social para explicar o aumento da criminalidade.” (NÓBREGA JÚNIOR, 2015, p.71).

${ }^{27}$ Uma das referências fundamentais de "teoria da eficácia coletiva" está em: Sampson, Raudenbush e Earls (1997). Para nós, a teoria da eficácia coletiva - amplamente devedora do conceito de "capital social" de Putnam - é, em seus fundamentos, muito semelhante à ecologia urbana, sendo, dela também, devedora.
} 
Quanto aos crimes das classes baixas, Sutherland aponta a "desorganização social" como fator determinante do crime entre as classes desfavorecidas. Dados como os que são arrolados abaixo são importantes na análise de Sutherland:

(a) As "regiões violentas" consistem em bairros pobres e deteriorados localizados em regiões centrais das cidades;

(b) As "comunidades violentas" consistem em regiões habitadas por populações de origens variadas, principalmente imigrantes;

(c) Os bairros com grande incidência de criminalidade violenta consistem em regiões que mantinham altos níveis de rotatividade residencial, com baixo poder de fixação da população local por longos períodos.

A segregação residencial, portanto, é fator operante na conformação das "regiões violentas". Deste modo, a diferenciação ecológica do fenômeno do crime, não deixa de revelar as desigualdades socioeconômicas entre as populações favorecidas e desfavorecidas. Pelo que as características sociais da população residente no território explicam as variações nas taxas de criminalidade.

\section{II - TEORIA DO AUTOCONTROLE DE MICHAEL R. GOTTFREDSON E TRAVIS RIRCH.}

\subsection{APRESENTAÇÃO}

Em “A general theory of crime” (1990), Michael Gottfredson e Travis Hirschi elaboraram - conforme encaminha o título de sua obra - uma "teoria geral da criminalidade" que relaciona o ato criminoso às "diferenças individuais na propensão ao cometimento de atos criminosos." (p.87). Eles pretendem apontar os requisitos comportamentais do ato criminoso sem, contudo, incorrerem numa visão determinística do criminoso. ${ }^{28}$ Esses autores tencionam, ainda, que a sua teoria seja, de algum modo, um aperfeiçoamento das "teorias clássicas [do crime] ou teorias do controle" (GOTTFREDSON; HIRSCHI, 1990, p.86), presentes, significativamente, nos escritos de

\footnotetext{
${ }^{28}$ Os autores argumentam que: "Parece imprudente tentar integrar uma teoria da escolha do crime com uma imagem determinista do ofensor, especialmente quando essa integração é desnecessária." (GOTTFREDSON; HIRSCHI, 1990, p.87).
} 
Jeremy Bentham. Eles argumentam que: "De fato, a compatibilidade da visão clássica do crime e a ideia de que as pessoas diferem em autocontrole é, em nossa visão, notável." (GOTTFREDSON; HIRSCHI, 1990, p.87). Os autores, então, afirmam que a teoria clássica "é uma teoria do controle social ou externo" (GOTTFREDSON; HIRSCHI, 1990, p.87), ao passo que teoria deles é sobre o autocontrole.

Gottfredson e Hirschi (1990), então, argumentam que é o grau de autocontrole apresentado por um indivíduo que irá determina sua maior ou menor propensão ao crime. Para esses autores, a maior parte dos atos criminosos são banais e triviais, precisam apenas uma preparação curta, têm poucas consequências permanentes e muitas vezes não produzem o resultado que o agressor esperava (GOTTFREDSON; HIRSCHI, 1990, p .16). Eles, ainda, observam que diferentes atos criminosos são intercambiáveis, porque estes mostram as mesmas características como o imediatismo e baixo grau de esforço. Assim, as diferenças entre crimes instrumentais e expressivos, ou entre crimes violentos e crimes não-coercitivos "são sem sentido e enganosas". (GOTTFREDSON; HIRSCHI, 1990, p.22).

De acordo esses autores, os indivíduos adquirem (ou não) a capacidade de controle da impulsividade ${ }^{29}$ e imediatismo (autocontrole) por meio da socialização familiar. Assim, os indivíduos com baixo autocontrole buscam a satisfação do prazer imediato sem considerar as consequências negativas em longo prazo, apresentando uma propensão a ceder a oportunidades momentâneas e a não adiar gratificações.

\footnotetext{
Socialização Familiar (bem ou mal sucedida) $\rightarrow$ (Baixo ou Alto) Autocontrole $\rightarrow$ Propensão à criminalidade

Cadeias causal: Relacionamento entre socialização familiar, autocontrole e delinquência na teoria geral do crime de Gottfredson e Hirschi (1990).
}

De acordo com o mencionado supra, Gottfredson e Hirschi (1990) sustentam que: “[...] a principal causa do baixo autocontrole parece, portanto, ser uma ineficaz criação de filhos [...] [,] "educação defeituosa" ou "negligência" na casa é a causa primária do crime.” (p.97). Eles afirmam que é necessário levar em consideração "a relação entre

\footnotetext{
29 Eles escrevem que: “O ato criminoso proporciona uma gratificação imediata dos desejos. Uma característica importante das pessoas com baixo autocontrole é, portanto, uma tendência a responder a estímulos tangíveis no ambiente imediato, a ter uma orientação concreta para o 'aqui e agora'. As pessoas com alto autocontrole, ao contrário, tendem a adiar a gratificação.” (GOTTFREDSON; HIRSCHI, 1990, p.89, grifo original).
} 
condição familiar e delinquência." (GOTTFREDSON; HIRSCHI, 1990, p.97). Assim, a instituição social fundamental para a prevenção do crime é a família ${ }^{30}$.

Viapiana (2006) resume a teoria do autocontrole nos seguintes termos:

[...] a teoria do autocontrole combina uma teoria da natureza humana segundo a qual estão presentes no indivíduo tanto a tendência para ações boas como para más, com a noção de que as pessoas aprendem valores morais e legais associados às boas ou más ações e, ainda, reserva ao indivíduo certo espaço para uma decisão racional para certas atitudes em detrimento de outras, pelo crime ou pelo não crime. (p.111).

Esse elemento de "cálculo", contudo, é feito de maneira diferente de indivíduo para indivíduo. ${ }^{31}$ Mas, o tema o interesse próprio e do egoísmo está presente na teoria do autocontrole. ${ }^{32}$ Gottfredson e Hirschi (1990) afirmam que: "pessoas com baixo autocontrole tendem a ser egocêntricas, indiferentes ou insensíveis ao sofrimento e às necessidades dos outros." (p.89). A premissa sobre a "natureza humana" é de que as pessoas perseguem, naturalmente, os seus próprios interesses e, a menos que sejam socializadas em contrário (no seio da família), elas usarão quaisquer que sejam os meios disponíveis para alcançar seus objetivos egocêntricos. É desta maneira que Robert (2005) resume que a teoria do crime de Gottfredson e Hirschi termina por definir "[...] o crime como um auto de fraude ou de força no intuito de satisfazer o próprio interesse.” (p.117).

A relação entre "natureza humana" e "socialização" está no fato de que:

(a) Premissa sobre a natureza humana: a pessoas tendem a ser egoístas e buscar os seus próprios interesses;

\footnotetext{
30 “A implicação mais ampla desta discussão é que, para qualquer fator, seja familiar, comunitário ou societal, para influenciar o autocontrole e, assim, os comportamentos ofensivos e análogos, deve ter um impacto na eficácia dos pais [...]. " (GOTTFREDSON; HIRSCHI, 1990, p.65). Os autores chegam a propor que os pais sejam supervisionados pelo Estado na criação dos seus filhos.

31 "Enquanto o prazer alcançado pelo ato é direto, óbvio e imediato, o sentimento do risco não é óbvio, nem direto, e, em qualquer caso, são maiores. Segue-se que, embora haja pouca variabilidade entre as pessoas na capacidade de ver os prazeres do crime, haverá uma variabilidade considerável na capacidade de calcular sentimentos de risco potenciais [...]. Assim, as dimensões do autocontrole são, a nosso ver, fatores que afetam o cálculo das consequências de seus atos ". (GOTTFREDSON; HIRSCHI, 1990, p.95).

${ }^{32}$ Hare (2013) aponta que o "cálculo" narcisista em Freud é o equivalente, em terminologia literária, de "cálculo" egoísta na teoria Hobbesiana.
} 
(b) Premissa sobre a socialização: uma socialização familiar bem sucedida encaminha as pessoas para não serem egoístas e para levarem em conta o interesse das outras pessoas.

De modo que, Gottfredson e Hirschi (1990) sustentam que:

(a) “[...] a principal causa do baixo autocontrole parece, portanto, ser uma ineficaz criação de filhos [...] (p.97);

(b) [...] "educação defeituosa" ou "negligência" [da família] [...] é a causa primária do crime." (p.97).

De maneira que, Gottfredson e Hirschi (1990) afirmam que é fundamental considerar a relação entre condição familiar e delinquência.

\subsection{ANÁLISE COMPARATIVA}

Tal tese ocupa, na Criminologia, um lugar de destaque entre as teorias que remetem o crime à estrutura psíquica do indivíduo e à dinâmica da socialização intrafamiliar. Aqui, também temos uma teoria que pode ser situada no nível interpessoal de análise do crime. Embora, os autores não tirem, em nenhum momento de sua elaboração, os olhos do indivíduo, o qual explica o crime sem, contudo, ser a "causa" do crime.

Há uma aparência de aproximação à concepção de Becker (1968) sobre a "teoria da escolha racional do crime" ${ }^{33}$. Mas, tal aproximação não é automática. Embora permita "certo espaço para a decisão racional" por parte dos indivíduos - conforme aponta Viapiana (2006) -, Gottfredson e Hirschi (1990) entendem que, ao contrário de uma capacidade para tomar decisões, o baixo autocontrole demarca uma incapacidade psíquica do indivíduo em controlar impulsos de realização imediata dos desejos. Estaríamos, aqui, situados não na esfera do indivíduo "calculista" que procura maximizar seus ganhos, e sim no âmbito de um indivíduo que não tem habilidade de analisar as

\footnotetext{
${ }^{33}$ Por isso, os autores informam que se trata de uma "uma teoria da escolha do crime". (GOTTFREDSON; HIRSCHI, 1990, p.87
} 
consequências nocivas (uma vez que se trata de um sujeito egocêntrico) dos seus atos. Temos aqui um sujeito impulsivo, não um planejador. O elemento do autointeresse é mais forte do que o elemento do "cálculo racional". 34

Há também uma relação com a teoria de Sutherland (2014 [1940]), uma vez que tanto Gottfredson e Hirschi (1990) quanto Sutherland (2014 [1940]) dão importância à "supervisão familiar". De fato, a teoria geral do crime pretende ser uma teoria afinada com as teorias do controle social (Cf. GOTTFREDSON; HIRSCHI, 1990, p.85). Neste sentido, as crianças não diferem, original ou naturalmente, em seu autocontrole ${ }^{35}$, tal diferença é desenvolvida, sobretudo, em sua educação familiar. A diferença em autocontrole é, principalmente, resultado da socialização familiar. O baixo autocontrole, então, é explicado por déficits que resultam da "ausência de cultivo [nurturance], disciplina ou treino." (GOTTFREDSON; HIRSCHI, 1990, p.95). Deste modo: "A principal causa do baixo autocontrole parece ser uma ineficaz criação de filhos." (GOTTFREDSON; HIRSCHI, 1990,p. 97).

Entre as condições consideradas necessárias para uma educação/socialização "bem-sucedida", nos termos dos autores, estão:

(a) Supervisão parental: para que as crianças desenvolvam autocontrole, elas precisam de pais que observem o seu comportamento;

(b) Empenho parental: os pais devem ser capazes de reconhecer os comportamentos egoísticos, impulsivos e anti-sociais;

(c) Disciplina: os pais devem reprovar ${ }^{36}$ os comportamentos egoísticos, impulsivos e anti-sociais, logo que a criança os manifeste (GOTTFREDSON; HIRSCHI, 1990).

Para Gottfredson e Hirschi (1990) tais etapas educativas não ocorreram quando se constata um indivíduo que possui baixo autocontrole. Por isso - contrariando Sutherland (2014 [1940]) - eles formulam que:

\footnotetext{
${ }^{34}$ É isso que os autores querem informar ao postularem que "as dimensões do autocontrole são, a nosso ver, fatores que afetam o cálculo das consequências de seus atos." (GOTTFREDSON; HIRSCHI, 1990, p.95).

${ }^{35}$ Embora tendam a ser egocêntricas.

${ }^{36}$ A disciplina, neste sentido, consiste, em termos behavioristas, não recompensar o comportamento antisocial e recompensar o comportamento pró-social.
} 
Nenhum grupo social conhecido, seja criminoso ou não criminoso, tenta ativamente ou intencionalmente reduzir o autocontrole de seus membros. A vida social não é reforçada pelo baixo autocontrole e suas consequências. Pelo contrário, a exibição dessas tendências prejudica as relações de grupo harmoniosas e a capacidade de alcançar fins coletivos. Esses fatos negam explicitamente que uma tendência ao crime é um produto da socialização, da cultura ou do aprendizado positivo de qualquer tipo. (GOTTFREDSON; HIRSCHI, 1990, p.9596, grifo nosso).

Em síntese, a socialização intencional, nos grupos, não é realizada para reduzir o autocontrole de seus membros, mas para aumentar autocontrole dos membros. Assim sendo, quando um indivíduo manifesta baixo autocontrole é porque a sua socialização foi deficiente, sobretudo em termos da socialização familiar. Tal tese parece-nos frágil quando se sabe, com Peralva (2000) e Viapiana (2006) que a influência de grupos pares - entre os adolescentes - encaminha uma socialização intencionalmente elaborada para reduzir o autocontrole dos seus membros. A regra é não se reprimir, quebrar as regras, superar os limites, assumir e desafiar o risco. Esse fato leva-nos a considerar um sério limite da teoria da socialização presente na teoria do crime de Gottfredson e Hirschi.

Contra a teoria da anomia - de Merton e seus discípulos -, mas, também, contra a teoria da associação diferencial de Sutherland, Gottfredson e Hirschi (1990) afirmam que:

Os traços que compõem baixo autocontrole são algo que não são propícios à realização de metas individuais de longo prazo. Pelo contrário, impedem a realização educacional e ocupacional, destroem as relações interpessoais e prejudicam a saúde física e o bem-estar da economia. Tais fatos negam explicitamente a noção de que a criminalidade é uma rota alternativa para os objetivos obtidos por meio de avenidas legítimas. (p.96).

No entanto, a explicitação de "tais fatos" nas citações de Gottfredson e Hirschi (1990), acima, não são suficientes para desqualificar nem a teoria de Sutherland nem a de Merton, as quais explicam melhor que do que a teoria do autocontrole os crimes de chamados de colarinho branco. Ao nosso modo de ver, a teoria do autocontrole explica melhor os crimes expressivos ${ }^{37}$, os crimes violentos e a "baixa" criminalidade. Ao passo que tanto a teoria de Sutherland quanto a de Merton - mostraremos no decorrer deste

\footnotetext{
${ }^{37}$ Crimes em que há agressão física ou coerção das vítimas.
} 
texto a teoria do crime de Merton - explicam melhor os crimes não-coercitivos, os crimes instrumentais ${ }^{38}$ e a "alta" criminalidade.

Como mencionado acima, Gottfredson e Hirschi (1990) não definiram o crime em termos jurídicos, uma vez que do ponto de vista deles uma mesma ação, quando realizada em diferentes contextos, pode ser definida como criminoso ou não criminoso ( $\mathrm{Cf}$. GOTTFREDSON; HIRSCHI, 1990, p. 175). Para eles, a definição de crime é o ponto inicial essencial de sua teoria: "O conceito central de uma teoria do crime deve ser o próprio crime." (GOTTFREDSON; HIRSCHI, 1990, p.175). Assim, o crime é, para Gottfredson e Hirschi (1990), composto por atos banais e triviais, que não exigem alta inteligência, grandes habilidades ou preparação especializada, são, usualmente, investidas que têm poucas consequências permanentes e muitas vezes não produzem o resultado que o agressor esperava (Cf. GOTTFREDSON; HIRSCHI, 1990, p.16). Isto é, atos criminosos demonstram a característica de serem intercambiáveis, porque revelam qualidades como a impulsividade e pequena parcela de esforço.

Tal definição da natureza do crime não permaneceu indiscutível na literatura, conforme aposta Robert (2005):

Sua ambição de generalidade foi criticada: ela não convém a certos tipos de criminalidade (o crime organizado ou a delinquência econômico-financeira. [...] Ela sofreu, ainda, com a revitalização das teorias anteriores - notadamente da elaboração mertoniana - que ela havia considerado categoricamente refutada. (p.118).

Portanto, o "crime de colarinho branco" é, geralmente, é reputado como exemplo de um tipo de crime que não pode ser explicado pela teoria do autocontrole (Cf. FRIEDRICHS; SCHWARTZ, 2008). Contudo, Friedrichs e Schwartz (2008) apontam que há complementariedades entre a teoria do autocontrole - "teoria geral do crime" de Gottfredson e Hirschi (1990) - a teoria do "aprendizado social" de Sutherland. Eles, ainda, entendem que há convergência entre a teoria de Gottfredson e Hirschi (1990) e a teoria da desorganização social. De fato, Matsueda (2008) sinaliza plena compatibilidade entre a teoria do autocontrole e a teoria da desorganização social. Surpreendentemente, Rosenfeld e Messner (2008) deduzem complementaridades entre a teoria do autocontrole

\footnotetext{
${ }^{38}$ Crimes de corrupção, fraude e estelionato, os quais não são acompanhados de agressão física ou coerção
} das vítimas. 
e a teoria da anomia de Merton, ensaiando uma correlação das duas em sua própria Institucional-Anomie-Theory.

De qualquer modo, Gottfredson e Hirschi (1990, p.180ss; 2001; 2008, p.226ss) questionam a tese de que a sua teoria não explica os "crimes de colarinho branco", contraargumentando, por exemplo, de que esta modalidade de crimes tão somente exibe diferenças graduais em relação aos crimes habituais.

Magalhães (2015) percebe que Gottfredson e Hirschi (1990) ao formularem que habilidades especiais não são exigidas para a prática de um crime, estão se fundamentando na teoria das atividades rotineiras de Cohen e Felson (1979). Assim, há uma afinidade entre a teoria do autocontrole e a teoria das oportunidades ou teoria das atividades rotineiras. Conforme ele explicita:

Crimes como roubo, estupro e homicídio exigiriam apenas a aparência de força física superior ou a posse de algum instrumento de força (armas). Crimes contra propriedade podem exigir força física e destreza, mas, na maioria dos casos, nada mais que o que se exige para as atividades rotineiras da vida. A maioria dos crimes aconteceria em locais próximos à residência do agente - $\mathrm{o}$ arrombador geralmente anda pela cena do crime e percebe a oportunidade -, além disso, procura casas que estejam abertas e se concentra em bens portáteis independentemente do valor que tenham no mercado. Finalmente, os autores analisam as condições necessárias para a ocorrência de um crime. Neste ponto pretendem fazer a articulação entre a definição de crime que buscam nos clássicos, os padrões empíricos da atividade criminosa e a noção de criminalidade, ou de propensão individual para a prática de crimes. De uma definição de crime, que foi esboçada acima, deduzem um perfil do criminoso. Para fazer a articulação, trabalham com a "abordagem das atividades rotineiras" (routine activity approach) de Cohen e Felson (1979). Nesta perspectiva, crimes requerem um ofensor motivado, ausência de vigilância eficiente e alvos disponíveis. (MAGALHÃES ,2015, p.40).

Finalmente, toda a elaboração de Gottfredson e Hirschi (1990) inicia apontando a sua derivação das: "teorias clássicas [que] no conjunto [...] são hoje denominadas teorias do controle.” (p.85, grifo original; Cf. HIRSCHI [2002 [1969]). O apelo de Gottfredson e Hirschi (1990) para que o Estado supervisione a educação parental sobre os filhos não deixa de revelar certa relação - embora distante em vários termos - com a teoria da eficácia coletiva.

Com efeito, é uma fraqueza para este modelo explicativo o fato - nem sempre excepcional - de que pessoas criadas numa mesma família optarem por seguir caminhos divergentes em relação à pratica criminosa. 


\section{III - TEORIA DA ANOMIA (STRAIN) DE ROBERT K. MERTON.}

\subsection{APRESENTAÇÃO}

Merton (1970 [1949]) inicia o seu texto "Estrutura social e anomia" com a seguinte afirmação:

Até há pouco tempo - e outrora muito mais -, podia-se falar de uma acentuada tendência nas teorias psicológicas e sociológicas, de atribuir o funcionamento defeituoso das estruturas sociais as falhas do controle social sabre os imperiosos impulsos biológicos do homem. A imagem das relações entre o homem e a sociedade insinuada por esta doutrina é bastante clara, mas é muito questionável. (p.203).

O fato é que Merton (1970 [1949]) intenta demonstrar como determinadas estruturas sociais exercem uma pressão específica sobre alguns membros da sociedade levando-lhes a adotar comportamentos desviantes das normas dos comportamentos aceitos. Nestes termos, para Merton (1970 [1949]), o "desvio"39 emerge como uma reação normal de certos indivíduos a uma dada situação social e a sua análise "pretende proporcionar um enforque sistemático [...] [das] [...] fontes sociais e culturais do comportamento transviado." (p.204). ${ }^{40}$

Então, Merton (1970 [1949]) apresenta a sua tese de que, entre os diversos elementos sociais e culturais (variáveis) importantes nessa situação do desvio criminal, dois são fundamentais:

O primeiro consiste em objetivos culturalmente definidos, de propósitos e interesses, mantidos como objetivos legítimos para todos, ou para membros diversamente localizados da sociedade. [...].

\footnotetext{
${ }^{39}$ Afastamento de uma norma moral ou legal, arbitrárias ou não. O termo "desvio" foi popularizado por Merton e por Becker (2008 [1963]).

${ }^{40}$ Merton (1970 [1949]) formula que: "Nosso objetivo principal e descobrir como e que algumas estruturas sociais exercem uma pressão definida sobre certas pessoas da sociedade, para que sigam conduta nãoconformista, ao invés de trilharem o caminho conformista. Se pudermos localizar grupos peculiarmente sujeitos a tais pressões, deveremos esperar encontrar proporções moderadamente elevadas de comportamento desviado em tais grupos, não porque os seres humanos, neles compreendidos, sejam compostos de tendências biológicas diferentes, mas porque elas estão reagindo normalmente à situação social na qual se encontram." (p.204, grifo original). Um pouco antes, Merton (1970 [1949) afirmara que: "[...] as perspectivas sociológicas têm contribuído cada vez mais a análise do comportamento que se desvia das normas prescritas, pois qualquer que seja o papel dos impulsos biológicos, ainda permanece de pé a questão de se saber por que a frequência do comportamento desviado varia dentro de estruturas sociais diferentes, e por que sucede que os desvios têm diferentes formas e moldes em estruturas diferentes. Hoje, como outrora, temos muito que aprender sobre os processos pelos quais as estruturas sociais geram as circunstancias em que a infração dos códigos sociais constitui uma reação 'normal' (isto é, que pode ser esperada)." (pp.203-204, grifo nosso).
} 
Um segundo elemento da estrutura cultural define, regula e controla os modos aceitáveis de alcançar esses objetivos. Cada grupo social, invariavelmente, liga seus objetivos culturais a regulamentos, enraizados nos costumes ou nas instituições, de procedimentos permissíveis para a procura de tais objetivos. Estas normas reguladoras não são necessariamente idênticas às normas técnicas ou de eficiência. Muitos procedimentos que do ponto de vista de indivíduos isolados seriam os mais eficientes na obtenção ao dos valores desejados - o exercício da força, da fraude, do poder - estão excluídos da área institucional da conduta permitida. Por vezes os procedimentos desabonados incluem algo que seria eficiente para o grupo em si mesmo, por exemplo, os tabus hist6ricos contra a vivissecção, ou a respeito das experiências médicas, ou a análise sociológica das normas "sagradas" - desde que o critério de aceitabilidade não e a eficiência técnica, mas sim os sentimentos carregados de valores (apoiados pela maior parte dos membros do grupo, ou por aqueles capazes de promover tais sentimentos através do uso simultâneo do poder e da propaganda). Em todos os casos, a escolha dos expedientes para se esforçar na obtenção dos objetivos culturais é limitada pelas normas institucionalizadas. (MERTON, 1970, p.205, grifo nosso).

Como podemos inferir do trecho, os dois elementos supra referidos - (1) os objetivos culturais (realização pessoal, profissional, econômica, etc.) tidos por legítimos para todos e (2) os modos aceitáveis de alcançar tais objetivos (as "regras do jogo", os sistemas normativos de condutas, etc.) - não poucas vezes entram em conflito, tanto no próprio sistema social quanto "na cabeça" dos indivíduos. Conforme apontam Cerqueira e Lobão (2004, p.259), são frequentes as situações em que ocorrem a impossibilidade de o indivíduo atingir metas por ele desejadas, por três fatores fundamentais:

a) Diferenças de aspirações individuais e os meios disponíveis;

b) Oportunidades bloqueadas;

c) Privação relativa.

A articulação desses fatores - conforme uma expressão de Merton (1970 [1949]): “[...] analiticamente separáveis embora se misturem em situações concretas [...]." (pp,204-205) - ocasiona a prática de desvios pela tensão (strain) entre aquilo que é proposto como objetivo legítimo ao alcance de todos numa mesma sociedade e as chances reais de um determinado indivíduo situado numa dada posição social alcançar tais metas pelos meios tidos como legítimos. Algo semelhante à desigualdade das oportunidades estudada por Boudon (1981) - numa sociedade democrática baseada na meritocracia. Com efeito, Boudon - tal como Chinoy (1975) apontara - enxerga que a meritocracia, 
numa sociedade do achievement, contribui para aumentar a tensão e o descontentamento de inúmeros indivíduos com a "justiça" e "justeza" do sistema social, levando alguns a optarem pela vida criminosa com vistas a alcançarem os fins a despeito dos meios, conforme a noção de "tensão" de Merton.

Assim, essa tensão entre as metas socioculturais recomendadas pelo sistema social e as reais condições de alcançá-las pelos meios legítimos, sobretudo, para certos indivíduos, apontaria para um rompimento - a anomia -; as normais sociais entrariam em conflito com os valores de um indivíduo ou uma subcultura, os valores exigindo um comportamento que as normas legítimas dificultam. Pelo que o comportamento criminoso consiste, elementarmente, num rompimento das normas. Os fins socioculturais passam ser tomados - por alguns indivíduos e subculturas - como sendo mais importantes do que as normas sobre a legitimidade dos meios utilizados. Temos assim, a situação em que os alguns sujeitos se tornam - na linguagem mertoniana - hiperconfomistas quanto aos fins e incorfomistas quantos aos meios. De sorte que temos a situação a qual Touraine (2000) chamou de "redefinição da anomia" (p.12) por Merton. Isto é, a "dissociação das condutas conforme sua orientação em direção a fins, ou aos meios de atingi-los." (TOURAINE,2000, p.12). Por um lado, há a ambivalência das metas sociais e dos meios de alcança-las legitimamente ${ }^{41}$. Por outro, tem-se que

[...] a decomposição das normas e dos vínculos tradicionais introduz um individualismo destruidor, que se traduz, por sua vez, na prioridade da busca pelo dinheiro [ou sucesso profissional ou financeiro] a qualquer preço. Uma forte dessocialização faz desaparecer as normas e os grupos que as representam, e produz esse encontro direto entre as necessidades sociais e a recusa das regras. (TOURAINE, 2000, p.12).

Em síntese, os parâmetros morais que definem os limites da ambição individual se enfraquecem fazendo emergir uma racionalidade instrumental direcionada por um individualismo renitente, autointeressado e transgressor que afiança ao desviante que a realização dos seus objetivos pessoais - amplamente solidário das metas socioculturais são justificáveis, mesmo se para alcançá-los ele se utilize dos meios socialmente reprovados.

\subsection{ANÁLISE COMPARATIVA}

${ }^{41}$ Vide o conceito de "desorganização social" de Chinoy (1975, p.646) informado em nota anterior (nota 7). 
A teoria de Merton situa-se no nível estrutural da análise sociológica ${ }^{42}$. Embora não deixe de lado - ao menos implicitamente, como vai acontecer nas análises funcionalistas - a participação do indivíduo no processo geral. Um elemento inconsciente (não-reflexivo) aparece na teoria de Merton, trata-se de uma "frustação" resultante da constatação de uma privação relativa à distância percebida (pelo indivíduo) entre o ideal de sucesso celebrado pelo sistema social e assumido pelo ator, mas só alcançado por alguns, e a possibilidade de alcançar tais metas pelos meios socialmente aprovados. De tal frustração emana uma espécie de "cálculo" sobre os "outros meios" possíveis (embora desabonados) para alcançar as metas socioculturais assumidas como pessoais. ${ }^{43}$

Não é em vão que - em sua revisão/ampliação da teoria da anomia, Messner, Thome e Rosenfeld (2008) admitam o cálculo racional do indivíduo como elemento fundamental no processo de reformulação dos meios alternativos para alcançar as metas socioculturais assumidas como suas:

Do ponto de vista subjetivo, as instituições desempenham um papel influente na orientação da "ação", que geralmente envolve algum tipo de relacionamento "meios-fins ". Os atores formulam objetivos (fins), e escolhem meios "adequados" (ou maneiras) de alcançar tais objetivos. A "adequação" dos meios pode ser determinada com referência a um padrão de racionalidade especificado. $O$ padrão preciso de racionalidade invocado difere dependendo da natureza dos fins. (p.165).

Prosseguindo em sua formulação, Messner, Thome e Rosenfeld (2008) afirmam que:

Quando uma norma está imbuída de [...] autoridade, o ator cumpre a norma porque o comportamento prescrito é "bom em si mesmo" e não é meramente um meio para algum outro fim. A autoridade moral das normas institucionais, no entanto, nunca é perfeita. Um tipo de controle secundário e utilitário acompanha invariavelmente o tipo moral nas sociedades em curso. Isso envolve um "cálculo da vantagem" enraizado em um apelo aos interesses (próprios), que pode assumir a forma de vantagens positivas, por um lado, ou consequências desvantajosas de outro. (p,166, grifo nosso).

\footnotetext{
${ }^{42}$ Ao definir o comportamento criminoso como algo "esperado" numa sociedade de achievement - em que os indivíduos vivenciam o conflito entre os objetivos culturais recomendados e os meios legítimos e as opções reais disponíveis para cada indivíduo conquistá-los -, Merton está redefinindo a noção de crime como "normal" de Durkheim, no qual se apoia.

${ }^{43}$ Assim, Merton (1970 [1949]) sinaliza que: "Muitos procedimentos que do ponto de vista de indivíduos isolados seriam os mais eficientes na obtenção dos valores desejados [...].” (p.205, grifo nosso).
} 
Os autores - ao ampliarem o escopo da abrangência da teoria da anomia - estão tornando explícito o papel do indivíduo, em sua reação às normas sociais; papel esse que já estava na elaboração de Merton, de maneira implícita.

Peralva (2000) - em sua pesquisa qualitativa sobre a aumento da criminalidade braseira pós-democratização política nos meados dos anos 80 - faz menções à teoria da anomia da Merton e "conversa" com ela a partir de sua pesquisa empírica sobre a "cultura do crime" nos morros do Rio de Janeiro e nas favelas de São Paulo. A autora articula uma interpretação própria do fenômeno por ela estudado, pela elaboração de sua concepção de "individualismo de massa". No entanto, Peralva (2000) comenta a teoria mertonina em algumas páginas do seu estudo (Cf. p.83ss, 84ss, 87ss, 126ss).

Opondo-se à tese do "ethos do ganho a qualquer preço" (p.83) Peralva (2000) propõe que:

Seja qual for a força inegável do argumento de Merton, não é exato que as desigualdades sociais no contexto do individualismo de massa conduzam necessariamente ao crime, por intermédio da revolta. Em todo caso, tal argumento não é suficiente para explicar a violência, porque, para a juventude pobre, a revolta se constrói em termos muitos mais complexos que aqueles derivariam das desigualdades em matéria de consumo. (pp.83-84).

No entanto, no conhecido "prefácio" ao livro de Peralva (2000), Touraine percebeu, aparentemente, mais dívida de Peralva para com a teoria de Merton do que ela própria admite.

A teoria da anomia de Merton foi mobilizada por Albert K. Cohen que a combinou com a teoria da associação diferencial de Sutherland - a primeira explicando a estatística da delinquência entre os jovens e a segunda para explicar a transmissão social do desvio - para que o próprio Cohen (1955) elaborasse a sua teoria da subcultura da delinquência. Desde os seus inícios a noção de subcultura está presente da teoria da Merton, tanto em termos da tensão (strain) quanto em termos da anomia propriamente dita.

Gottfredson e Hirschi (1990) foram críticos severos da teoria da anomia, eles supõem que depois do aprofundamento do estudo do crime realizados por eles e outros sociólogos, a teoria da anomia foi provada falsa e iria desvanecer no campo de estudo do crime. No entanto outros sociólogos como Agnew e White (1992) e Agnew (1992, 1993) trabalharam para ampliar a teoria da anomia e formularam a general strain theory.

Como já mencionado supra, Messner, Thome e Rosenfeld (2008) apresentaram uma versão ampliada da teoria da anomia em sua Institucional-Anomie Theory. Ao incluir 
considerações parsonianas junto com a elaboração primitiva de Merton, a InstitucionalAnomie Theory deixa espaço explícito para a atuação voluntarista dos indivíduos, junto com a ação também explícita das estruturas e processos sociais.

Em relação à teoria do autocontrole, a teoria de Merton distancia-se deste modelo ao supor - embora de maneira implícita, conforme dito anteriormente - um sujeito racional, cuja reação aos desequilíbrios do sistema social em que vive é "normal"44, e que avalição dos meios alternativos para alcançar seus próprios fins (egoísticos) demonstra uma habilidade cognitiva (ou inteligência) que o situa, no mínimo, na média dos homens inteligentes, e não abaixo da média, como prevê a teoria do autocontrole.

Em relação à teoria da associação diferencial (ou do aprendizado social), o elemento cultura e, até mesmo, subcultura presente na teoria mertoniana apontam para alguma afinidade entre esses dois modelos teóricos.

\section{OBSERVAÇÕES FINAIS}

Estabelecendo uma relação entre as três teorias, podemos propor que a teoria do autocontrole, embora esteja situada no nível interpessoal de análise sociológica, tem um forte apelo individualista. Assim, ela explicaria - dentro dos limites já apresentados anteriormente neste texto - o papel do indivíduo, autointeressado, calculista e atuante no cenário do crime.

A teoria associação diferencial está fundamentalmente situada no nível interpessoal da análise sociológica. Seu apelo cultural (aprendizado, socialização, etc.) e sua visada socioestrutural (necessidade de controle social, aumento da eficácia coletiva, etc.) tornam-na relevante na demonstração dos relacionamentos entre o nível individual e o estrutural nos fenômenos criminais.

A teoria da tensão/anomia, pretende ser uma abordagem do crime situada no nível estrutural da análise sociológica. Mas, implicitamente, ela aponta para as dinâmicas individual e interpessoal (cultural, subcultural) do crime.

Cada uma dessas três teorias tem seus méritos e suas fraquezas. Parece-nos, entretanto, que é possível correlacionar cada uma delas para explicar níveis diferentes da análise do crime. Para nós, nenhuma delas sozinhas dá conta de explicar as múltiplas causas e os múltiplos componentes da criminalidade, seja em seu aspecto instrumental ou

\footnotetext{
${ }^{44}$ Isto é, esperada ou estruturalmente consequente.
} 
expressivo, em termos violentos ou não-coercitivos. Cada uma apresenta seus próprios limites e cada uma preenche a lacuna explicativa deixada pela outra.

Assim, a tentativa de operacionalizar diferentes teorias explicativas sobre os fenômenos do crime, parece-nos ser o caminho mais viável para o estudo sistemático e abrangente do crime. O certo é que, cada teórico enxerga a sua teoria como a mais abrangente e a mais explicativa dos fatos aos quais pretende estudar. No entanto, ao compararmos uma teoria com outras, percebemos o quanto cada uma delas apresenta as "exceções" que a teoria concorrente não consegue explicar e a sua contribuição para a explicação desses casos excepcionais, embora essa nova elaboração - quase sempre também deixe de fora outros casos que constituem uma exceção dentro na nova teoria elaborada.

A sociologia do crime está repleta de teorias sobre as "causas" e os "fatores" do crime. O nosso contexto de descoberta está bem suprido. É no contexto de justificação das teorias existentes que a sociologia do crime está se desenvolvendo, nos anos recentes. Como mostram os novos estudos que tentam ampliar e validar teorias que já havia sido dadas por superadas.

É fato que precisamos aprender a selecionar aquelas que apresentam certo grau de convergência e complementariedade para explicar os diferentes componentes presentes no cenário do crime (indivíduo, contexto cultural, interações e estrutura social), elaborando, deste modo, uma explicação dos "casos" mobilizando tais teorias correlacionadas.

O que Messner, Thome e Rosenfeld (2008) e Rosenfeld e Messner (2008) fizeram, recentemente, merece ser considerado como uma importante iniciativa de unificar teorias divergentes sobre o crime a partir da cobertura das lacunas que uma teoria pode realizar em relação àquela que deixa a lacuna aberta. Esses autores, na renovação da teoria da anomia, assumem que uma única teoria não daria conta de explicar a complexidade transversal do fenômeno do crime. E, a partir deste ponto, elaboram a InstitutionalAnomie Theory combinando a teoria do autocontrole, a teoria da associação diferencial e a teoria da "tensão" para dar conta do amplo leque de causas e consequências atuantes no complexo fenômeno do crime.

Do nosso ponto de vista, as três teorias aqui selecionadas cumprem as funções de apresentarem algum mínimo grau transversalidade. Certamente, colidem em alguns pontos. Ainda resta muito por fazer. No entanto, parece-nos não haver dúvidas que estas 
três teorias conjuntamente dão conta da explicação dos fatores causais do fenômeno do crime, por complementarem umas às outras naqueles casos em que se percebe uma "lacuna" explicativa que a outra preenche significativamente.

\section{BIBLIOGRAFIA}

AGNEW, Robert. Foundation for a General Strain Theory of crime anda delinquency. In: Journal of Research in Crime and Delinquency. Vol.28, 1992, p.47-87.

Why do They do It?An examination of the intervening mechanisms between social control variables and delinquency. In: Journal of Research in Crime and Delinquency. Vol. 30, 1993, p. 245-266.

; WHITE, Helene R. 1992. An empirical test of General Strain Theory. In: Criminology. Vol. 30, 1992, p.475-499.

BECKER, Gary S. Crime and punishiment: an economic approach. In: Journal of Political Economy. Vol.76, 1968, 169-217.

BECKER, Howard S. Outsiders. Estudos de sociologia do desvio. Rio de Janeiro: Zahar, 2008 [1963].

BOUDON, Raymond. A desigualdade das oportunidades: A mobilidade social nas sociedades industriais. Brasília, DF: Editora da UNB, 1981.

CERQUEIRA, Daniel; LOBÃO, Waldir. Determinantes da criminalidade: arcabouços teóricos e resultados empíricos. In: DADOS - Revista de Ciências Sociais. Rio de Janeiro, vol.47, n.02, 2004, p.233-269.

CHINOY, Ely. Sociedade: uma Introdução à Sociologia. São Paulo: Cultrix, 1975.

CLARK, Burton R. Educating the expert society. San Francisco: Chandler, 1962.

COHEN, Albert. K. Delinquent Boys. New York: Free Press, 1955.

COHEN, Lawrence; FELSON, Marcus. Social change and crime rate trends: A Routine Activity approach. In: American Sociological Review, Vol. 44, n.04, 1979, p. 588-608.

DALGALARRONDO, Paulo. Psicopatologia e semiologia dos transtornos mentais. Porto Alegre: Editora Artes Médicas, 2000.

FREITAS, Wagner C.P. . Espaço urbano e criminalidade: lições da Escola de Chicago. São Paulo: Editora Método, 2004.

FRIEDRICHS, David. O.; SCHWARTZ, Martin. D. Low self-control and high organisational control: The paradoxes of white-collar-crime. In: GOODE, Erich. (Ed.). Out of control: Assessing the general theory of crime. Stanford, California: Stanford University Press, 2008, p.145-159. 
GOTTFREDSON, Michael R. ; HIRSCHI, Travis. A general theory of crime. StanfordCalifornia: Stanford University Press, 1990.

HARE, Robert D. Sem Consciência. O mundo perturbador dos psicopatas que vivem entre nós. Porto Alegre: Editora Artmed, 2013.

HIRSCHI, Travis. Causes of delinquency. ( $2^{\circ}$ edition). New Brunswick, London: Transaction Publishers, 2002 [1969].

HIRSCHI, Travis; GOTTREDSON, Michael. R. (2001). Self-control theory. In: PATERNOSTER, Raymond; BACHMAN, Ronet. (Ed.), Explaining criminals and crime. Essays in contemporary criminological theory. Los Angeles: Roxbury Publishing Company, 2001, p. 81-96.

HIRSCHI, Travis; GOTTREDSON, Michael. R. (2008). Critiquing the critics: The authors respond. . In: GOODE, Erich. (Ed.). Out of control: Assessing the general theory of crime. Stanford, California: Stanford University Press, 2008, p.217-231.

JACOBS, Jane. Morte e vida de grandes cidades. São Paulo: Martins Fontes, 2000 [1961].

KAPLAN, Harold I.; SADOCK, Benjamin J.; SADOCK, Virgínia A. Compêndio de psiquiatria: ciências do comportamento e psiquiatria clínica. $9^{\mathrm{a}}$ ed. Porto Alegre: Artes médicas, 2007.

MATSUESA, Ross. L. On the compatibility of Social Disorganation and Self-Control. In: GOODE, Erich. (Ed.). Out of control: Assessing the general theory of crime. Stanford, California: Stanford University Press, 2008, p.102-126.

MEAD, George H.. Espíritu, persona y sociedad: desde el punto de vista del conductismo social. $1^{\text {a }}$ edición, Buenos Aires, Editorial Paidós, 1968 [1934].

MERTON, Robert K. Estrutura social e anomia. In: Rio de Janeiro: Editora Mestre Jou, 1970 [1949], p.203-234.

MESSNER, Steven F.; THOME, Helmut; ROSENFELD Richard. Institutions, Anomie, and Violent Crime: Clarifying and Elaborating [. In: International Journal of Conflit and Violence [IJCV]. Vol. 02, n.02, 2008, pp. 163-181.

NÓBREGA JÚNIOR, José Maria Pereira da. Teorias do crime e da violência: uma revisão da literatura. In: BIB. São Paulo, n.77, 2015, p.69-89.

PATERNOSTER, Raymond; BACHMAN, Ronet. (Ed.), Explaining criminals and crime. Essays in contemporary criminological theory. Los Angeles: Roxbury Publishing Company, 2001.

PERALVA, Angelina. Violência e democracia. O paradoxo brasileiro. São Paulo: Editora Paz \& Terra, 2000. 
ROBERT, Phillip. La sociologie du crime. Paris: Éditions La Découvert, 2005.

ROSENFELD, Richard; MESSNER, Steven F. Self-Control, Anomie, and Social Institutions. In: GOODE, Erich. (Ed.). Out of control: Assessing the general theory of crime. Stanford, California: Stanford University Press, 2008, p.90-101.]

SUTHERLAND, Edwin H. The Professional Thief. Chicago: University of Chicago Press, 1937.

A criminalidade de colarinho branco. In: Revista Eletrônica de Direito Penal e Política Criminal. UFRGS, vol.02, n.02, 2014 [1940], p.93-103.

TARDE, Gabriel. As leis da imitação. Porto: Rés Editora, 2000 [1890].

THOMAS, William Isaac; THOMAS, Dorothy Swaine. The child in America: behavior problems and programs. New York: Knopf Publishing House, 1928.

TOURAINE, Alain. Prefácio. In: PERALVA, Angelina. Violência e democracia. O paradoxo brasileiro. São Paulo: Editora Paz \& Terra, 2000, p.11-16.

VIAPIANA, Luiz Tadeu. Economia do crime: uma explicação para a formação do criminoso. Editora: Age Editora, 2006.

WHYTE, William Foote. Sociedade de esquina. Rio de Janeiro: Jorge Zahar, 2005 [1943]. 